\title{
The morphometric variation of islands in the middle and lower Yangtze River: A variational analytical explanation
}

\author{
Xiaofang Liu ${ }^{\text {a }}$, He Qing Huang ${ }^{\text {a,*, Gerald C. Nanson }}{ }^{\text {b }}$

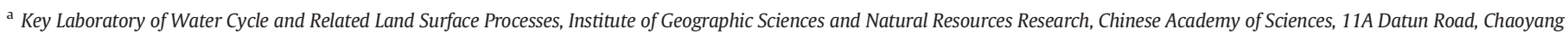 \\ District, Beijing 100101, China \\ b School of Earth and Environmental Sciences, University of Wollongong, NSW 2522, Australia
}

\section{A R T I C L E I N F O}

\section{Article history:}

Received 4 October 2015

Received in revised form 4 March 2016

Accepted 7 March 2016

Available online 8 March 2016

\section{Keywords:}

Anabranching river

River islands

Variational approach

Equilibrium

Yangtze River

\begin{abstract}
A B S T R A C T
Anabranching rivers are formed of islands of various shapes and this study applies a variational analytical approach to explain the morphology of islands of a particular basic shape. A theoretically modeled anabranching river is developed based on observations from the middle and lower Yangtze River, which alternates between a single channel and a two-channel anabranching reach with islands approximately triangular in planform such that one anabranch is longer than the other. The equilibrium condition of the model river is derived from a variational investigation of basic relationships of flow continuity, channel boundary resistance, bedload transport, and energy conservation in the anabranching river. We demonstrate that when such a system reaches stationary equilibrium the triangular planform of the island is determined by the proportions of water and sediment passing through the two channels. We also show that the shorter straight channel takes a larger proportion of sediment relative to its proportion of water. For the island to take a streamlined morphology, the difference between the proportions of water and sediment discharge entering each channel needs to be as small as possible. When the paired proportions of water and sediment discharge take different values, the streamlined morphologies of the island vary in a wide range. In comparison with the measured morphologies of the five islands located in the middle-lower Yangtze River, the theoretically determined lengths of the islands are remarkably consistent, varying from the corresponding field measurements by a range of $< \pm 10 \%$.
\end{abstract}

(c) 2016 Elsevier B.V. All rights reserved.

\section{Introduction}

Anabranching rivers consist of multiple channels separated at effective or bankfull stage by islands or ridges (trains of islands) of approximately bankfull height. This type of river has been widely observed and now has been recognized as an independent river channel pattern (Nanson and Knighton, 1996; Latrubesse, 2008, 2015; Ashworth and Lewin, 2012; Carling et al., 2014; Frias et al., 2015).

Anabranching rivers evolve from growth of mid-channel bars, flow separation and avulsion, and many other processes during which riparian vegetation can also exert a significant effect (e.g., Nanson and Knighton, 1996; Tooth and Nanson, 1999, 2000; Millar, 2000; Gurnell and Petts, 2002; Tooth and McCarthy, 2004; Latrubesse and Franzinelli, 2005; Marchetti et al., 2013; Carling et al., 2014; Latrubesse, 2015). As a result, they exhibit a variety of anabranching planforms, with islands normally taking complex morphologies (e.g., Meshkova and Carling, 2012, 2013; Frias et al., 2015; Latrubesse, 2015). To characterize island morphometry in anabranching rivers, the ratio of island length-to-width has been widely used. Some islands consist of essentially one-dimensional, downstream-oriented alluvial

\footnotetext{
* Corresponding author.

E-mail address: huanghq@igsnrr.ac.cn (H.Q. Huang).
}

ridges but these are a relatively uncommon type (e.g., Wende and Nanson, 1998; Tooth and Nanson, 1999). The islands in most rivers are two-dimensional in planform, and while differing in shape from one to another, their length-to-width ratios are within a limited range that Baker and Kochel (1979) and Tooth and Nanson (2000) showed statistically to be between about 3 and 4 . This consistency of shape in these two-dimensional islands has been explained as the effect of streamlining that makes the drag from the boundary of an island a minimum (Komar, 1983). Hence, streamlining implies an adjustment of island morphology to the hydrology such that minimal stream energy loss occurs (Zanoni et al., 2008). When more observations are gathered together, however, Meshkova and Carling (2013) demonstrated that the length of river islands shows a degree of nonlinear proportionality with width in many environments, with the length-to-width ratios of all islands varying in a wide range of 1.2 to 8 . Hence they argued that length-to-width ratios varying between 3 and 4 are only the ideal cases for river islands.

In contrast to statistical analyses of the morphological characteristics of river islands observed at many places on Earth and some on Mars, a number of scientists have tried to identify theoretical and empirical bases for distinguishing anabranching river from other types (e.g., Knighton and Nanson, 1993; Ni, 1994; Millar, 2000; Eaton et al., 2010). This approach stems from investigations of the physical 
mechanisms leading to the development of different river planforms (e.g., Leopold and Wolman, 1957; Parker, 1976). For multiple-channel river systems in northern Australia, Nanson and Huang (1999); Tooth and Nanson (1999, 2000); Jansen and Nanson (2004, 2010), and Huang and Nanson (2007) proposed that they are commonly formed to maintain an efficient conveyance of water and sediment. The islands in these systems can remain stable and divide the flow for 10002000 years, so clearly such features represent long-term, stable, equilibrium conditions (Tooth et al., 2008).

A pattern of relatively long single-thread reaches and anabranching around large two-dimensional islands is the dominant river planform along the middle and lower Yangtze River (Yu and Lu, 2005). Where it is a single channel, the Yangtze River along the study reach is some 1100 to $2200 \mathrm{~m}$ wide with depths averaging about 12 to $22 \mathrm{~m}$. In such a wide and relatively shallow river the character of the banks play a very minor role in determining what is a self-adjusting alluvial channel morphology dominated by the primary drivers of flow continuity, flow resistance, and bedload transport (Huang and Nanson, 2000, 2002; Huang et al., 2014). This situation is in contrast to much smaller rivers where cohesive vegetated banks can have a profound influence on bank strength and hence channel form (Nanson and Huang, 1999; Millar, 2000; Parker et al., 2007; Eaton and Giles, 2009).

Over a length of more than $800 \mathrm{~km}$, extending from Yichang, about $30 \mathrm{~km}$ downstream from the Three Gorges Dam, to the mouth of the river at Jiangyin (Fig. 1), numerous river islands are present, some of which are older than several hundred years (Institute of Geography of CAS et al., 1985). They differ considerably in shape with length-towidth ratios between 1.2 and 8.2 (Yu and Lu, 2005). Where the channel of the Yangtze River slightly meanders, very large islands occur in some of the bends and take an approximately triangular morphology (Fig. 1A-E). These islands have been present and relatively stable for decades, in some cases for several hundred years (Institute of Geography of CAS et al., 1985). Their occurrence as stable long-term features in an alluvial system provides an opportunity to examine the applicability of equilibrium theory for alluvial channel flow proposed by Huang and Nanson (2000) and Nanson and Huang (2008) in anabranching rivers. For anabranching rivers in environments where channel slope cannot be readily adjusted, Huang and Nanson (2007) applied equilibrium theory for alluvial channel flow by highlighting the role that the formation of narrow and long ridge-form islands can play in altering width/depth ratios and thereby changing the efficiency of sediment transport. The purpose of this study is to extend the theoretical work of Huang and Nanson (2007) on linear islands to environments where anabranching is characterized with the occurrence of a relatively wide island in the middle of a river cross section. Within the context of equilibrium theory for alluvial channel flow and the associated variational analytical approach proposed by Huang and Nanson $(2000,2002)$, this study determines the morphology of an island of a particular shape in the river on the condition that there is a possibility for flow in all the channels to locally adjust their slope to some degree. These theoretical results are tested against field observations from five island-formed anabranching reaches located in the middle and lower Yangtze River, as shown in Fig. $1 \mathrm{~A}-\mathrm{E}$.

\section{Self-adjusting mechanism of alluvial channel flow}

\subsection{Flow in a single alluvial channel}

For alluvial channel flow, the following widely applied ManningStrickler flow resistance relationship needs to be satisfied:

$V\left(=\frac{Q}{A}\right)=c_{f} \sqrt{g R S}\left(\frac{R}{d}\right)^{1 / 6}$

where $V, Q, A, c_{f}, g, R, S$, and $d$ are, respectively, the average flow velocity, flow discharge, channel cross-sectional area, frictional coefficient, acceleration of gravity, hydraulic radius, channel slope, and bed sediment size.

Over the past 100 years, a large number of formulae have been proposed to determine the bedload flux, and in these the shear stress of flow has been taken as the major driving factor (e.g., du Boys, 1879; Meyer-Peter and Müller, 1948; Wong and Parker, 2006; Huang, 2010). Among these formulae, that developed by Huang is applied here for two reasons. Firstly, in contrast to a variety of empirical assumptions
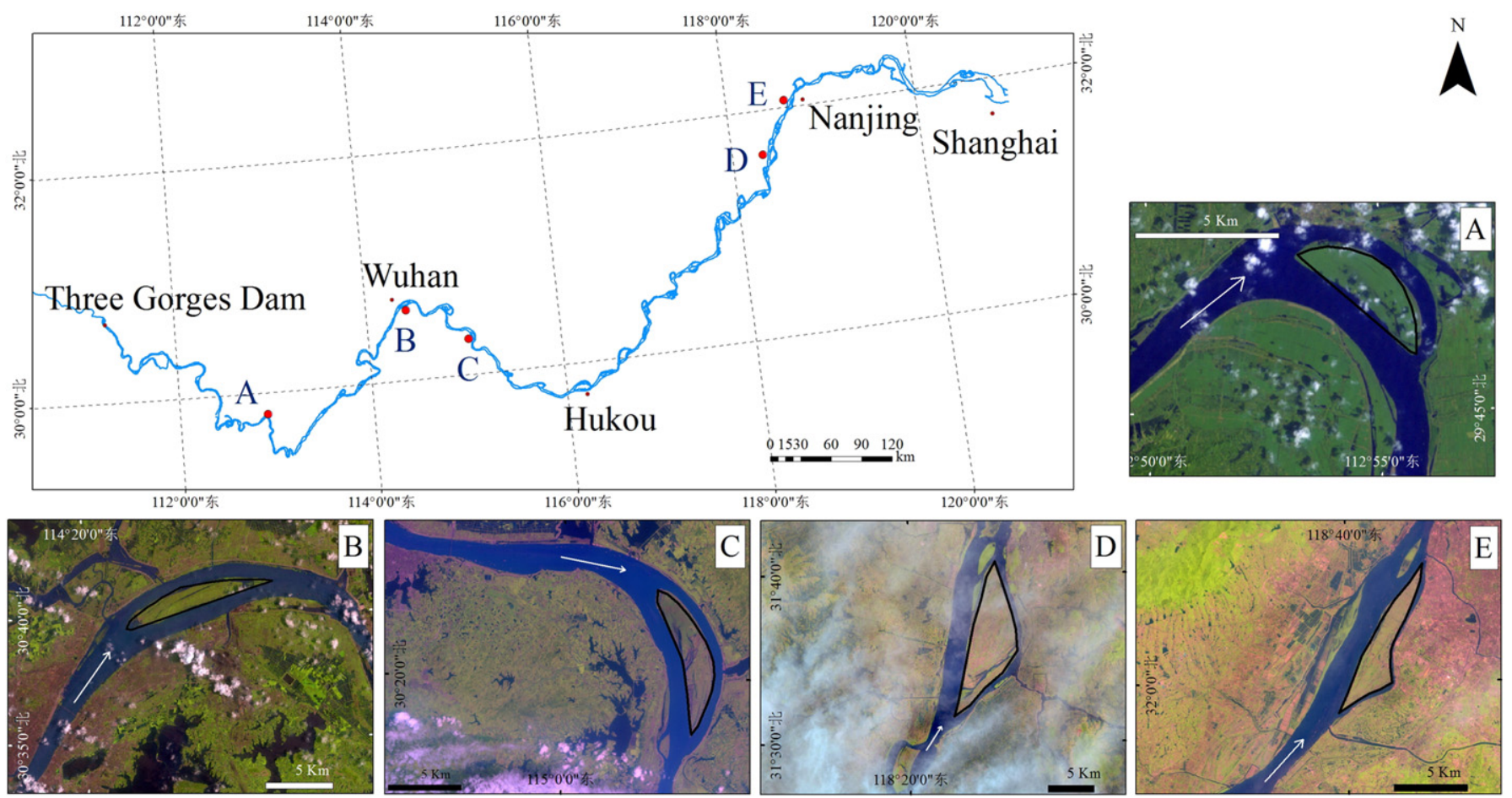

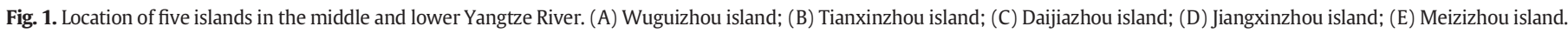


embedded in the development of previous formulae, the Huang formula is based on a theoretical relationship exhibited when the complex interactions reach a stationary equilibrium state among the three essential components of a river (channel geometry, bedload transport, and flow resistance; Huang and Chang, 2006). Secondly, the Huang formula yields bedload transport rates highly consistent with experimental observations and provides a higher level of prediction for channel geometry of rivers, including very large rivers such as the middle and lower Yangtze River where suspended sediment represents nearly $90 \%$ of the total sediment load (Huang et al., 2014).

The bedload transport formula developed by Huang (2010) takes the form of

$q_{b}^{*}=6\left(\tau_{o}^{*}-\tau_{c}^{*}\right)^{5 / 3}$

where $q_{b}{ }^{*}, \tau_{o}^{*}$, and $\tau_{c}^{*}$ are the dimensionless bedload transport rate per unit channel width, dimensionless average flow shear stress, and dimensionless critical shear stress, respectively. These three dimensionless parameters are defined as

$q_{b}{ }^{*}=\frac{q_{b}}{\sqrt{\left(\frac{\rho_{s}}{\rho}-1\right) g d^{3}}} ; \quad \tau_{0}^{*}=\frac{R S}{\left(\frac{\rho_{s}}{\rho}-1\right) d} ; \quad \tau_{c}^{*}=0.047$

where $q_{b}$ is the dimensional bedload transport rate per unit channel width, $\rho_{s}$ is the specific density of sediment grains, and $\rho$ is the specific density of water.

To understand the self-adjusting mechanism of river channel geometry, Huang and collaborators (Huang and Nanson, 2000, 2001, 2002; Huang et al., 2002; Huang and Chang, 2006; Nanson and Huang, 2008) demonstrated that introducing a channel shape factor as a variational variable is necessary to embody the change in the channel crosssectional geometry, i.e., width/depth ratio for a rectangular crosssection:

$\zeta=\frac{W}{D}$

where $W$ and $D$ are the channel width and average depth, respectively.

By integrating Eq. (4) into Eqs. (1) and (2) using the analytical approach proposed by Huang and Nanson (2000), we can show that for given $Q, S$, and $d$, the transport rate of bedload over the full channel width $Q_{S}\left(=q_{b} W\right)$ can then be expressed as a function of channel shape factor $\zeta$ in the form of

$Q_{s}=K_{1} \zeta^{3 / 8}(\zeta+2)^{1 / 4}\left[K_{2} \frac{\zeta^{3 / 8}}{(\zeta+2)^{3 / 4}}-\tau_{c}^{*}\right]^{5 / 3}$

where parameters $K_{1}$ and $K_{2}$ are defined separately as

$$
\begin{aligned}
K_{1} & =6 \sqrt{\left(\frac{\rho_{s}}{\rho}-1\right) g d^{25 / 16}\left(\frac{Q}{c_{f} \sqrt{g S}}\right)^{3 / 8} ; K_{2}} \\
& =\frac{S^{13 / 16}}{\left(\frac{\rho_{s}}{\rho}-1\right) d^{15 / 16}}\left(\frac{Q}{c_{f} \sqrt{g}}\right)^{3 / 8} .
\end{aligned}
$$

Eq. (5) explains how the rate of bedload transport passing through an alluvial channel changes with an adjustment in the variational variable (the channel shape factor) $\zeta$. For given values of $Q d$, and $S$, research has demonstrated that $Q_{S}$ reaches a maximum at an appropriate value of $\zeta_{m}$ (Huang and Nanson, 2000, 2002; Huang and Chang, 2006; Nanson and Huang, 2008). Physically, this optimal condition defines a special equilibrium state of alluvial channel flow, i.e., stationary equilibrium (Huang et al., 2004). By letting $d Q_{s} / d \zeta=0$, we can determine from Eq. (5) that when $Q_{S}$ reaches a maximum the following flow condition needs to be satisfied:

$\frac{\tau_{o}^{*}-\tau_{c}^{*}}{\tau_{c}^{*}}=\frac{5\left(\zeta_{m}-2\right)}{16}$.

From Eq. (7) we clearly see that for given $Q, d$, and $S$, an optimum channel width/depth ratio $\zeta_{m}$ can be directly determined and consequently a maximum bedload discharge can be derived from Eq. (5). In addition, Eq. (7) shows that $\zeta_{m}$ has a lowest value of 2 , which is consistent with the best hydraulic section when a river channel reaches the critical state for incipient motion of bed sediment. By combining Eq. (7) with Eqs. (1) to (4), we found that the optimal channel width/ depth ratio $\zeta_{m}$ can be determined from the following complex relationship:

$\frac{\left(\zeta_{m}-2\right)^{\frac{5}{3}} \zeta_{m}^{\frac{6}{13}}\left(\zeta_{m}+2\right)^{\frac{1}{13}}}{\left(5 \zeta_{m}+6\right)^{\frac{3}{13}}}=59.68 \frac{Q_{s}}{Q^{\frac{6}{13}} d^{\frac{35}{26}}}$.

Because few rivers have a width/depth ratio $>1000$ and for $\zeta_{m}$ to be $>2$, which is the threshold for the incipient motion of bed sediment, $\zeta_{m}$ is assumed to take integer values from 3 to 1000 . The left-hand side of Eq. (8) can then be expressed approximately as

$\frac{\left(\zeta_{m}-2\right)^{\frac{5}{3}} \zeta_{m}^{\frac{6}{13}}\left(\zeta_{m}+2\right)^{\frac{1}{13}}}{\left(5 \zeta_{m}+6\right)^{\frac{3}{13}}} \approx 0.4882 \zeta_{m}{ }^{2.0289}, r^{2}=0.9986$.

Consequently, combining Eqs. (8) and (9) yields

$\zeta_{m}=10.6844\left(\frac{Q_{S}}{Q^{\frac{6}{13}} d^{\frac{35}{26}}}\right)^{\frac{1}{2.0289}}$.

As demonstrated by Huang and Nanson (2000, 2002, 2007), the condition of $Q_{S}=Q_{s m a x}$ for given values of $Q, d$, and $S$ is equivalent to the condition of $S=S_{\min }$ for given values of $Q d$, and $Q_{s}$. Hence, for given values of $Q$ and $d$ the minimum energy slope $S_{\min }$ can be determined by incorporating Eq. (7) into Eq. (5):

$S_{\min }=0.006148 \frac{d^{\frac{15}{13}}}{Q^{\frac{6}{13}}} \frac{\left(5 \zeta_{m}+6\right)^{\frac{16}{13}}\left(\zeta_{m}+2\right)^{\frac{12}{13}}}{\zeta_{m}^{\frac{6}{13}}}$.

For $\zeta_{m}$ to vary from 3 to 1000 , the complex relationship between $S_{\text {min }}$ and $\zeta_{m}$ in Eq. (11) can be approximated and then combined with Eq. (10), yielding

$S_{\min }=2.8851 \frac{Q_{s}^{0.8143} d^{0.0576}}{Q^{0.8374}}$

Eqs. (10) and (12) demonstrate that for given sediment discharge, sediment size, and flow discharge, the slope and geometry of a straight single channel at stationary equilibrium can be quantitatively determined.

\subsection{Flow in an anabranching river with a triangular island}

The triangular islands in the middle and lower Yangtze River varies considerably in morphologies as shown in Fig. 1A-E; and to simplify mathematical analysis, a simple, two-channel anabranching river is modeled theoretically here. Flow in the two channels is assumed steady and approximately uniform and both channels in the modeled anabranching system take a rectangular cross section in which $W_{1}$ and $D_{1}$ are the channel width and depth of channel 1 and $W_{2}$ and $D_{2}$ are their counterparts in channel 2 (Fig. 2A and B). The total flow discharge in the anabranching system is $Q$ and the proportions of water in the two channels are $P_{w 1}$ and $P_{w 2}$, respectively. As a result, the following 
(A)

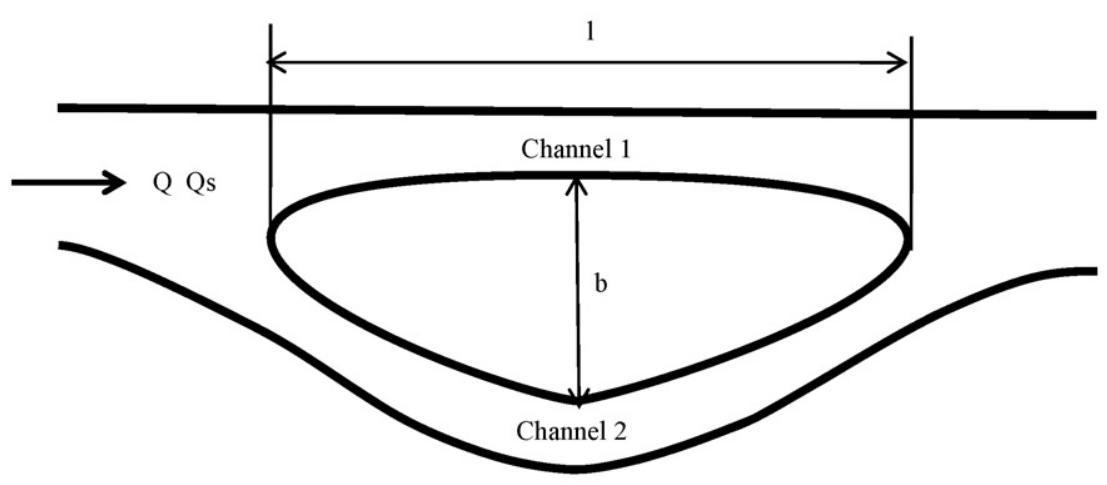

(B)

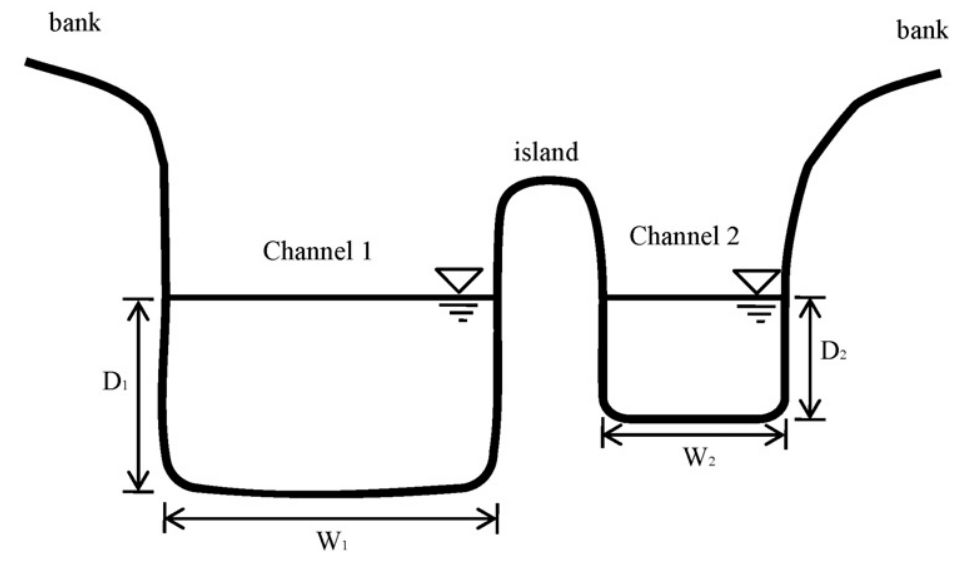

Fig. 2. (A) Planform of the two-channel anabranching river. (B) A simplified cross-sectional form for a two-channel anabranching river.

relationships are maintained:

$Q_{1}=P_{w 1} Q$

$Q_{2}=P_{w 2} Q$

$P_{w 2}=1-P_{w 1}$

where $Q_{1}$ and $Q_{2}$ are the flow discharges in channels 1 and 2, respectively.

Similarly, the total bedload discharge in the river system is assumed to be $Q_{s}$, and the proportions of bedload discharge in the two channels are separately $P_{s 1}$ and $P_{s 2}$; so the following relationships are maintained:

$Q_{s 1}=P_{s 1} Q_{s}$

$Q_{s 2}=P_{s 2} Q_{s}$

$P_{s 2}=1-P_{s 1}$

where $Q_{s 1}$ and $Q_{s 2}$ are the bedload discharges in channels 1 and 2, respectively.

For energy conservation, the head loss of flow in the two channels is equal between the bifurcation and confluence points of the two channels. The head loss is composed generally of frictional head loss $h_{f}$ and local frictional loss $h_{j}$. In the uniform open channel flow, energy is dissipated mostly as friction and local loss is usually relatively small and can be ignored, such that the following relationship is satisfied:

$h_{f 1}=h_{f 2}$.
The head loss can be illustrated as a function of energy slope $S$ and the length of flow path, $L_{P}$, in the form of

$h_{f}=S \cdot L_{P}$.

It is apparent from Eqs. (15) and (16) that flow in channels 1 and 2 needs to satisfy the following relationship:

$\frac{S_{1}}{S_{2}}=\frac{L_{P 2}}{L_{P 1}}$

Field observations on the planforms of islands in the middle and lower Yangtze River (Fig. 1A-E) show that the two-channel system flows around an island that has the approximate form of an isosceles triangle, as presented in Fig. 2A where the island has a length of $l$ and a width of $b$. In the longer and slightly curved channel (channel 2), flow takes a path along the two equal sides of the triangle; while in the shorter straight channel (channel 1 ), flow runs along the third side or base of the triangle. The lengths of channels 1 and 2 (Fig. 2A), or $L_{P 1}$ and $L_{P 2}$, have relationships with the length and width of the island, or $l$ and $b$, as

$\left\{\begin{array}{l}L_{P 1}=l \\ L_{P 2}=\sqrt{l^{2}+4 b^{2}} .\end{array}\right.$

When the anabranching river as a whole achieves a stationary equilibrium state, flow in each channel needs to satisfy the condition of 
minimum energy slope. In terms of Eqs. (12) to (14), the minimum energy slope in two channels, or $S_{1} \mathrm{~min}$ and $S_{2} \mathrm{~min}$, can be determined as

$S_{1 \min }=2.8851 \frac{\left(P_{s 1} Q_{s}\right)^{0.8143} d^{0.0576}}{\left(P_{w 1} Q\right)^{0.8374}}$
$S_{2 \min }=2.8851 \frac{\left(P_{s 2} Q_{S}\right)^{0.8143} d^{0.0576}}{\left(P_{w 2} Q\right)^{0.8374}}$.

In Eq. (19), the grain size of bed sediment $d$ in the two branches is regarded as identical. This simplification is adopted because it has been observed in the middle and lower Yangtze River that the grain sizes of bed sediment in anabranches show only a slight difference (e.g., Yu and Lu, 2005). In addition, the power of $d$ in Eq. (19) takes a value of only 0.0576 and so any slight difference in sediment size will exert no significant influences on island morphology.

Incorporating Eqs. (18) and (19) into Eq. (17) yields

$\frac{\left(\frac{P_{s 1}}{P_{s 2}}\right)^{0.8143}}{\left(\frac{P_{w 1}}{P_{w 2}}\right)^{0.8374}}=\frac{\sqrt{l^{2}+4 b^{2}}}{l}$.

Furthermore, by combining Eqs. (13) and (14) into Eq. (10), the optimum channel width/depth ratios of the two channels, $\zeta_{1 m}$ and $\zeta_{2 m}$, can be determined as

$\zeta_{1 m}=10.6844\left(\frac{Q_{s}}{Q^{\frac{6}{13}} d^{\frac{35}{26}}} \frac{P_{s 1}}{P_{w 1} 1^{\frac{6}{13}}}\right)^{\frac{1}{2.0289}}$
$\zeta_{2 m}=10.6844\left(\frac{Q_{s}}{Q^{\frac{6}{13}} d^{\frac{35}{26}} \frac{P_{s 2}}{P_{w 2} 2^{\frac{6}{13}}}}\right)^{\frac{1}{2.0289}}$.

As a consequence, the relative change in the optimum channel width/depth ratios of the two channels can be determined by

$\frac{\zeta_{1 m}}{\zeta_{2 m}}=\frac{\left(\frac{P_{s 1}}{P_{s 2}}\right)^{0.4929}}{\left(\frac{P_{w 1}}{P_{w 2}}\right)^{0.2275}}$.

Apparent from Eqs. (20) and (22) is that the proportions of water and sediment discharge in each channel are interrelated with the morphology of the island and the geometry of each anabranch. This means that this type of anabranching river evolves from a complex interactive process among at least three variables.

\subsection{Morphology of the island in relation to $P_{s 1}$ and $P_{w 1}$}

The ratio of the width to the length of island $(b / l)$ is a very important factor reflecting the morphometry of the island in a two-channel river system and can be determined by incorporating Eqs. (13) and (14) into Eq. (20), yielding

$\frac{b}{l}=\frac{1}{2} \sqrt{\left(\frac{\left(\frac{P_{s 1}}{1-P_{s 1}}\right)^{0.8143}}{\left(\frac{P_{w 1}}{1-P_{w 1}}\right)^{0.8374}}\right)^{2}-1 .}$

We see from Eq. (23) that when $P_{w 1}=P_{s 1}=50 \%, b / l=0$. This means that in this case no island of a triangular planform will be present in the modeled anabranching river. However, this does not exclude the existence of the other forms of islands. Importantly, Eq. (23) shows that only when $P_{s 1}>P_{w 1}$ is there a solution for $b / l$. This means that an island of a triangular planform can exist only when $P_{s 1}>P_{w 1}$. For given values of $P_{s 1}$ and $P_{w 1}$, the corresponding value of $b / l$ can be determined from Eq. (23) using a trial-and-error method. Fig. 3A presents a comparison of the planforms of the island when $P_{s 1}$ takes respective values of $61 \%$,
(A)
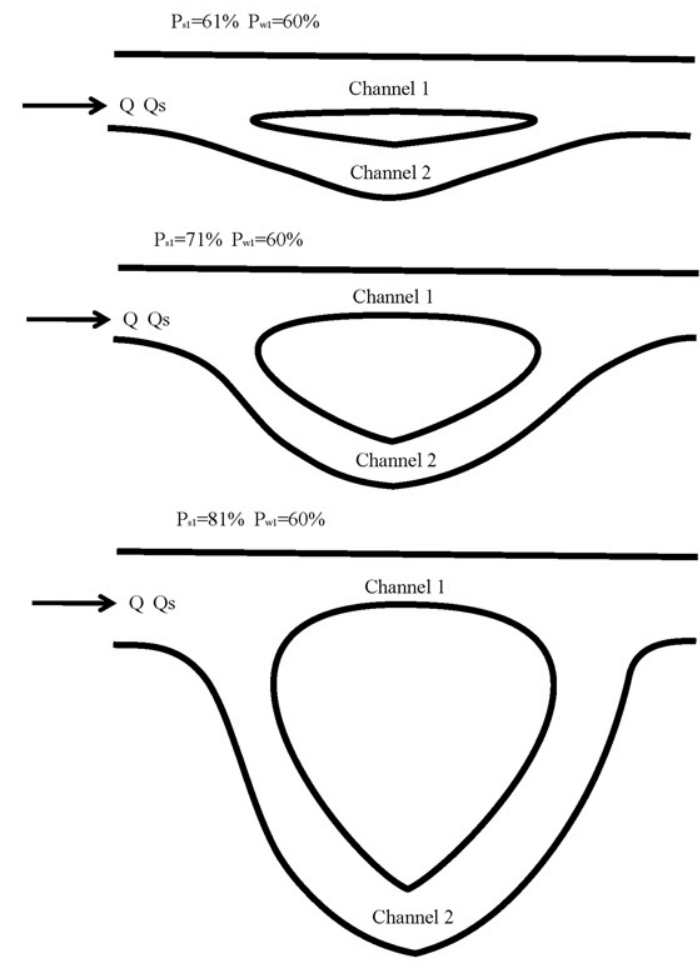

(B)
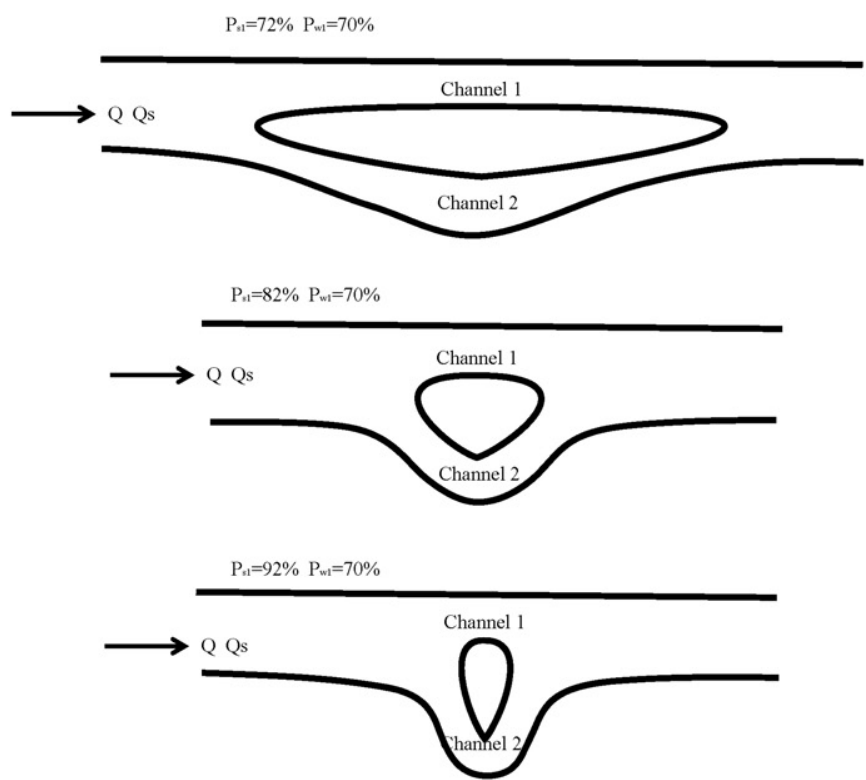

Fig. 3. (A) Morphologic variation of the island on the condition that $P_{s 1}$ takes respective values of $61 \%, 71 \%$, and $81 \%$ when $P_{w 1}=60 \%$ and the length of the island remains a constant. (B) Morphologic variation of the island on the condition that $P_{s 1}$ takes respective values of $72 \%, 82 \%$, and $92 \%$ when $P_{w 1}=70 \%$ and the width of the island remains a constant.

$71 \%$, and $81 \%$ on the condition that $P_{w 1}=60 \%$ and that the island length remains a constant. In the situation of $P_{s 1}=61 \%$, the island is relatively slender in planform and the ratio of the width to the length of island $(b /$ $l$ ) is about 0.11 . Nevertheless, when $P_{s 1}$ becomes $71 \%, b / l$ increases to 0.54 ; and when $P_{s 1}$ increases further to $81 \%$, the width of the island is larger than the length such that $b / l$ reaches 1.05 . 


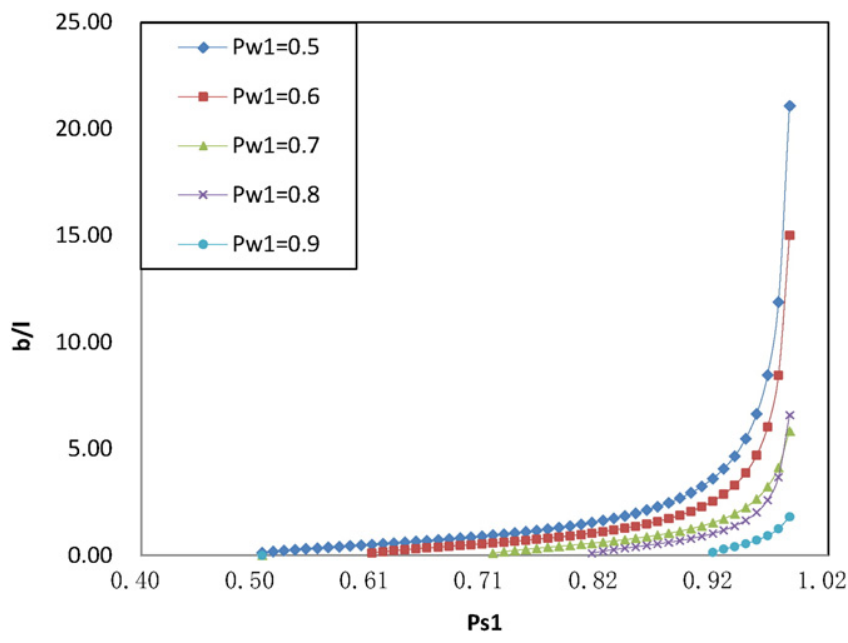

Fig. 4. Variation of $b / l$ with changes in $P_{s 1}$ and $P_{w 1}$ computed from Eq. (23).

Fig. 3B presents the planforms of islands when $P_{s 1}$ takes values of $72 \%, 82 \%$, and $92 \%$ on the conditions that $P_{w 1}=70 \%$ and that the width of the island remains a constant. Correspondingly, the value of $b / l$ increases from $0.18,0.68$ to 1.72 , and the length of the island becomes smaller and smaller.

Fig. 4 shows how the width-to-length ratio of the island, or $b / l$, responds to the changes in $P_{s 1}$ and $P_{w 1}$. With an increase in $P_{w 1}$, changes in $b / l$ are increasingly constrained within relatively tight bounds. More importantly, when $P_{w 1}$ remains a constant and $P_{s 1}$ increases, $b / l$ increases; while for a certain value of $P_{s 1}$, a decrease in $P_{w 1}$ causes $b / l$ to increase. Moreover, for a certain value of $P_{w 1}, b / l$ increases slowly at first; and after $P_{s 1}$ is greater than a certain value, $b / l$ increases more rapidly. As a whole, it is seen from Fig. 4 that $b / l$ varies in a wide range of around 0.13 to 21.08 , equivalent to the length-to-width ratios varying in a range of around 0.05 to 7.69 .

Theoretically, it is possible for $P_{w 1}$ and $P_{s 1}$ to take significantly different values; and yet this can produce unrealistic islands that present a highly obstructional (resistant) morphology to the flow, as shown in Fig. $3 \mathrm{~A}$ and B. This may explain why $P_{w 1}$ and $P_{s 1}$ take different and yet very similar values, as observed from real rivers by the Institute of Geography of CAS et al. (1985) and Luo (1989).

Table 1 presents a comparison of the channel geometries of a single channel river with the counterparts of a two-channel anabranching river when both these rivers achieve stationary equilibrium. It is noticeable that in the two cases of anabranching the total width of the two channels of the anabranching system is much larger than that of the equivalent single channel system, while the depths and the ratios of width-to-depth of the two channels are all smaller than their counterparts in the single channel system. This result means that anabranching with a triangular island usually develops in a wide valley where there is sufficient room for width adjustments by modification of the channels as well as the islands. This observation is consistent with field observations from the anabranching reaches in the middle and lower Yangtze River (You, 1984; Institute of Geography of CAS et al., 1985; Luo, 1989).
In addition, whatever proportion of water is allocated between the two channels in the two cases for an anabranching river where $P_{w 1}<50 \%$ or $P_{w 1}>50 \%$, the shorter straight channel 1 has a steeper slope and transports proportionately more sediment than water, while the longer curved channel 2 has a gentler slope and conveys proportionately less sediment than water. However, mean flow velocity in the two-channel anabranching system is slower than in the equivalent single channel system (Table 1).

\section{Verification of theoretical results in the field}

In order to test the veracity of these theoretical results derived from the equilibrium theory for alluvial channel flow in the modeled twochannel anabranching river, five large alluvial islands with an approximately triangular planform that separate river flow into two channels are selected along the middle and lower Yangtze River (Fig. 1). Wuguizhou island is located in the upper part of the middle Yangtze River with a length of $5.4 \mathrm{~km}$ and a maximum width of $1.5 \mathrm{~km}$ (Fig. 1A). It occurs within the river at a bend adjacent to the countytown of Jianli. Since 1994, about $88 \%$ of flow has been passing through the right-hand channel. The bankfull flow discharge passing through this reach is $22,000 \mathrm{~m}^{3} / \mathrm{s}$, and the corresponding proportions of water and sediment passing through the main channel are $88.4 \%$ and $90.3 \%$, respectively (Huang, 2008).

Tianxingzhou island is located in the northeastern area of Wuhan city: on the middle part of the middle Yangtze River. It has a length of $11.4 \mathrm{~km}$ and a maximum width of $1.7 \mathrm{~km}$ and occurs at a bend along a weakly meandering and anabranching reach with a sinuosity index of about 1.25 (Fig. 1B). Since the beginning of the 1970s, the majority of flow has been taking the right-hand channel. At bankfull stage, the proportions of water and sediment passing through the main channel are $70.8 \%$ and $72.6 \%$, respectively (Institute of Geography of CAS et al., 1985; Xu and Yue, 2008).

Daijiazhou island is located about $60 \mathrm{~km}$ downstream from Wuhan city and has a length of $10.4 \mathrm{~km}$ and a maximum width of $2.0 \mathrm{~km}$. Along this reach, flow takes a meandering and anabranching course with a sinuosity index of about 1.22 (Fig. 1C). Since 1965, the majority of flow has been taking the right-hand channel. At bankfull stage the proportions of water and sediment in the main channel are $56 \%$ and $58 \%$, respectively (Lv, 2011). The total bankfull flow discharge entering the divided channels around Tianxinzhou and Daijiazhou islands is essentially the same, about 40,500 $\mathrm{m}^{3} / \mathrm{s}$ (Yu and Lu, 2005; Cai and $\mathrm{Li}$, 2011).

Jiangxinzhou island is located near Maanshan city in the middle part of the lower Yangtze River and has a length of $17.6 \mathrm{~km}$ and a maximum width of $5.6 \mathrm{~km}$ (Fig. 1D). Near the downstream end of this island, two small islands have formed roughly in line with the main island, and these are not incorporated into the overall triangular island shape. Broadly, the Yangtze River here exhibits a straight two-channel anabranching form. Since 1860, the majority of flow has been taking the left-hand channel, and at bankfull stage the proportions of water and sediment passing into the main channel are $89 \%$ and $91.5 \%$, respectively (Institute of Geography of CAS et al., 1985; Guan, 2010; Hong and Liao, 2012; Lu et al., 2012; Yu et al., 2012).

Table 1

A comparison of the theoretically computed channel geometries using Eqs. (19) and (21) between a single channel river and a two-channel anabranching river in two cases.

\begin{tabular}{|c|c|c|c|c|c|c|c|c|}
\hline River & & $Q\left(\mathrm{~m}^{3} / \mathrm{s}\right)$ & $Q_{s}\left(\mathrm{~m}^{3} / \mathrm{s}\right)$ & $W(\mathrm{~m})$ & $D(\mathrm{~m})$ & $\zeta_{m}$ & $S_{\min }$ & $V(\mathrm{~m} / \mathrm{s})$ \\
\hline Straight single-channel reach & & 500 & 0.03 & 136.29 & 1.40 & 97.44 & 0.0005232 & 2.62 \\
\hline \multirow[t]{2}{*}{ Anabranching reach (case 1) } & Channel 1 & $125(25 \%)$ & $0.009(30 \%)$ & 65.92 & 0.90 & 73.66 & 0.0006246 & 2.11 \\
\hline & Channel 2 & $375(75 \%)$ & $0.021(70 \%)$ & 115.32 & 1.32 & 87.18 & 0.0004969 & 2.46 \\
\hline \multirow[t]{2}{*}{ Anabranching reach (case 2) } & Channel 1 & $375(75 \%)$ & $0.024(80 \%)$ & 117.70 & 1.26 & 93.16 & 0.0005546 & 2.53 \\
\hline & Channel 2 & $125(25 \%)$ & $0.006(20 \%)$ & 61.97 & 1.03 & 60.31 & 0.0004496 & 1.96 \\
\hline
\end{tabular}


Table 2

Bankfull hydrogeomorphic features of the five selected islands and their corresponding reaches in the middle and lower Yangtze River ${ }^{\mathrm{a}}$.

\begin{tabular}{|c|c|c|c|c|c|c|c|c|}
\hline Island & $\begin{array}{l}\text { Bankfull } \\
\text { flow } \\
\text { discharge } \\
\left(\mathrm{m}^{3} / \mathrm{s}\right)\end{array}$ & $\begin{array}{l}\text { Sediment } \\
\text { discharge } \\
(\mathrm{kg} / \mathrm{s})\end{array}$ & $\begin{array}{l}\text { Roughness } \\
n\end{array}$ & $c_{f}$ & $\begin{array}{l}P_{w 1} \\
(\%)\end{array}$ & $\begin{array}{l}P_{s 1} \\
(\%)\end{array}$ & $\begin{array}{l}P_{w 2} \\
(\%)\end{array}$ & $\begin{array}{l}P_{s 2} \\
(\%)\end{array}$ \\
\hline Wuguizhou & 22,000 & 423 & 0.0197 & 3.8 & 88.4 & 90.3 & 11.6 & 9.7 \\
\hline Tianxingzhou & 40,500 & 292 & 0.02035 & 3.7 & 70.8 & 72.6 & 29.2 & 27.4 \\
\hline Daijiazhou & 40,500 & 292 & 0.02035 & 3.7 & 56 & 58 & 44 & 42 \\
\hline Jiangxinzhou & 46,000 & 253 & 0.02165 & 3.5 & 89 & 91.5 & 11 & 8.5 \\
\hline Meizizhou & 46,000 & 253 & 0.02165 & 3.5 & 95 & 95.9 & 5 & 4.1 \\
\hline
\end{tabular}

a Note: (1) $P_{w 1}, P_{s 1}, P_{w 2}$ and $P_{s 2}$ denote the proportions of water and sediment discharges in channels 1 and 2, respectively. (2) Bankfull flow discharge, sediment discharge, bed-sediment size, roughness, and $c_{f}$ for the selected five islands are obtained from Yu and Lu (2005). (3) Water and sediment apportionments at bankfull in the anabranches of the five selected islands are obtained from Institute of Geography of CAS et al. (1985); Huang (2008); Yu and Lu (2005), and Lv (2011), respectively.

Meizizhou island is located near the central area of Nanjing city, with a length of $11.8 \mathrm{~km}$ and a maximum width of $2.7 \mathrm{~km}$ (Fig. 1E). Along this reach the Yangtze River develops a relatively straight anabranching planform, with the main flow taking the left-hand channel since 1860. At bankfull stage the proportions of water and sediment passing into the main channels are 95\% and 95.9\%, respectively (Yu and Lu, 2005). The bankfull discharges passing through Jiangxinzhou and Meizizhou reaches are nearly the same, about 46,000 $\mathrm{m}^{3} / \mathrm{s}$ (Yu and Lu, 2005; Cao, 2012).

Morphologies of the five islands were obtained from Landsat Archive images, which are downloaded from the USGS (U. S. Geological Survey, http://glovis.usgs.gov/). These images are selected in terms of the level of river flow that was approximately at bankfull stage along the five islands. In the selection, images taken after 2003 are excluded because the Three Gorges Reservoir started to impound water gradually to the highest level since then, which has caused considerable adjustment in river channel morphology downstream of the dam (Dai and Liu, 2013). The morphologies measured from the selected images and the corresponding hydrological conditions for the five islands are presented in Tables 2 and 3 and are used to verify our theoretical results computed according to Eq. (23).

These islands vary in size from 4.6 to $54 \mathrm{~km}^{2}$ and have floodplain surfaces mostly over $1 \mathrm{~m}$ higher than bankfull, supporting hundreds and in some cases thousands of inhabitants in farms and villages living mainly on agriculture cultivation and fishing. Natural levees along the boundaries of the islands are covered with dense reeds, while bushes/ trees grow well all over the lower floodplains. Strong dykes several meters high have been built up artificially along the boundaries between the lower and higher floodplains, allowing heavy trucks to transport materials usable for protecting the dykes. As a result, the cultivated land and residential houses on the islands have gained protection from the inundation of very large floods.
Table 3 presents a comparison of the theoretically computed island lengths using Eq. (23) and the measured island widths for the five islands on the middle and lower Yangtze River. It is shown clearly that the theoretically computed lengths of the five islands are consistent with their measured values when the actual maximum width for each island is used in the computations. Among the five islands, the theoretically computed length of Meizizhou island is mostly consistent with the field measurement, with a calculated value being only $2.51 \%$ less than that measured. In contrast, the computed length of Tianxingzhou island is the least consistent, with the calculated length being 9.90\% less than that measured. The differences between predicted and measured lengths for Wuguizhou, Daijiazhou, and Jiangxinzhou islands are $9.35 \%, 7.92 \%$, and $-5.03 \%$, respectively.

It is apparent from Table 3 that the theoretically computed island lengths are remarkably similar to the actual values. This demonstrates that the equilibrium theory based on a variational analysis of basic flow relationships not only has a sound theoretical basis but also provides a convenient and effective method for predicting morphology of long-lived stable islands in large alluvial anabranching river systems.

Despite this consistency, clear differences are apparent between the planform of an isosceles triangle representing the five islands and the real morphologies of the islands (Fig. 1A-E). The real morphologies of the islands are smoother than our modeled shape; and hence while our simplified method makes the computation convenient, a certain degree of accuracy is lost. Hence, our method is limited in application to islands with morphologies very similar to isosceles triangles, otherwise significant errors could result.

\section{Discussion}

In many environments, river islands display length-to-width ratios of between 3 and 4 , and this consistency has been explained as the effect of streamlining that keeps the drag developed by an island at a minimum (e.g., Baker and Kochel, 1979; Komar, 1983; Tooth and Nanson, 2000). Our theoretical investigation of the morphometric variation of islands of a triangular shape frequently occurred in the middle and lower Yangtze River shows that when the proportions of water and sediment discharge entering the two channels take very close values, the boundary resistance of an island achieves a minimum. This explains why the measured proportions of water and sediment discharge in the two channels separated by the selected islands in the middle and lower Yangtze River all adopt very similar paired values (Table 2). The apparent physical mechanism behind these results is that river islands develop their morphologies not only by minimizing their boundary drag but also by transporting water and sediment discharge through their bounding channels in a way that optimizes their flow efficiency, as required by the equilibrium theory for alluvial channel flow (Huang and Nanson, 2000, 2002; Nanson and Huang, 2008). Hence, the theoretical analysis presented in this study extends the usefulness of the physical principle of minimum drag in fluvial systems.

Table 3

Comparison of the measured and the theoretically calculated lengths for the five islands in the middle and lower Yangtze River ${ }^{\mathrm{a}}$.

\begin{tabular}{|c|c|c|c|c|c|c|c|}
\hline Island & $\begin{array}{l}\text { Month of } \\
\text { measurement }\end{array}$ & $\begin{array}{l}\text { Measured flow discharge } \\
\text { approximately at bankfull }\left(\mathrm{m}^{3} / \mathrm{s}\right)\end{array}$ & $\begin{array}{l}\text { Measured island } \\
\text { length-to-width ratio }\end{array}$ & $\begin{array}{l}\text { Measured island } \\
\text { width } b(\mathrm{~m})\end{array}$ & $\begin{array}{l}\text { Measured island } \\
\text { length } l_{f}(\mathrm{~m})\end{array}$ & $\begin{array}{l}\text { Calculated island } \\
\text { length } l_{t}(\mathrm{~m})\end{array}$ & Relative error $\frac{l_{t}-l_{f}}{l_{f}} \times 100(\%)$ \\
\hline Wuguizhou & 2000.9 & 21,133 & 3.58 & 1500 & 5367 & 5869 & 9.35 \\
\hline Tianxingzhou & 2002.7 & 41,003 & 6.72 & 1699 & 11,415 & 10,285 & -9.90 \\
\hline Daijiazhou & 2002.7 & 41,003 & 5.15 & 2018 & 10,393 & 11,216 & 7.92 \\
\hline Jiangxinzhou & 2002.6 & 45,300 & 3.16 & 5595 & 17,654 & 16,766 & -5.03 \\
\hline Meizizhou & 2002.6 & 45,300 & 4.33 & 2727 & 11,807 & 11,511 & -2.51 \\
\hline
\end{tabular}

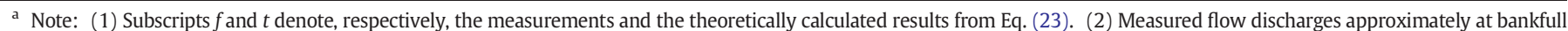

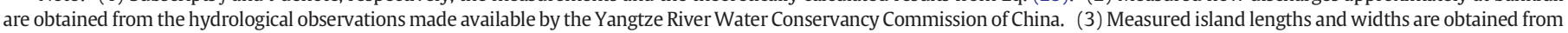
the Landsat satellite images downloaded from the website of USGS (http://glovis.usgs.gov/). 
Furthermore, it can be noted in Fig. 4 that for different islands, the paired values of water and sediment proportions are very different, leading to island length-to-width ratios varying in a considerable range. This demonstrates that there are many streamlined morphologies even for river islands of a triangular shape, consistent with the finding of Meshkova and Carling (2013) and Latrubesse (2015). While this study highlights the role of an adjustment in channel slope, it needs to point out that in the development of river islands of a triangular shape, channel slope adjustment is not the sole factor. Other factors may also lead to the development of this type of islands in rivers, such as confinement of river valleys, river bed gradients, and many more. Hence, care needs to be taken when applying the results of this study to interpret the development of anabranching rivers in other environments.

\section{Conclusions}

In environments where channel slope cannot be adjusted because of regional physical constraints, Huang and Nanson (2007) demonstrated the efficiency of anabranching for transporting water and sediment load imposed by the fluvial systems. Within the context of maximum flow efficiency, this study examines the hydrogeomorphic conditions leading to the morphometric variation of islands in the middle and lower Yangtze River by applying a variational analytical approach.

Two-channel anabranching with islands of isosceles triangular planform commonly occurs in the middle and lower Yangtze River. Our detailed variational analysis of basic flow relations of continuity, channel boundary resistance, bedload transport, and energy conservation in such systems shows that the planform of the island is interrelated with the geometries of the two channels and the relative proportions of water and sediment discharge entering the two. When the anabranching system reaches stationary equilibrium, the proportion of sediment discharge to that of water discharge into the short straight channel (i.e., the base of the triangle) is greater than that entering the longer secondary channel. This is because the shorter straight channel adopts a steeper slope while the longer curved channel a gentler one.

Furthermore, Table 1 demonstrates that the total width of the two channels is much larger than the width of a single-channel river. As a consequence, such anabranching formed with relatively wide islands can only develop in wide valleys or in the bends of valleys where there is sufficient room for width adjustments in the channels and the island.

This study selected five large islands from the middle and lower Yangtze River to evaluate the results of the detailed theoretical analysis. It has shown that the theoretically computed predicted lengths of the islands exhibit an acceptable degree of correspondence $(-9.90 \%$ to $+9.35 \%)$ to actual field measurements.

\section{Acknowledgements}

This study was carried out under the financial support of the National Natural Science Foundation of China (51179181, 41330751), an open fund from the State Key Laboratory of Hydroscience and Engineering at Tsinghua University (sk1hse-2011-B-03), the International Science \& Technology Cooperation Program of China (2013DFA91700), and the Discovery Project of ARC (Australia Research Council). The authors would like to thank the USGS for providing free Landsat satellite data on the middle and lower Yangtze River, and the Yangtze River Water Conservancy Commission of China for permission to access the observed hydrological data. Paul Carling, Edgardo Latrubesse, and an anonymous reviewer are all thanked for their valuable comments, which significantly enhanced the quality of this paper.

Symbols

A channel cross-sectional area

b island width $c_{f} \quad$ frictional coefficient in flow resistance relationship

d sediments size

D average channel depth

$D_{1} \quad$ average channel depth of channel 1

$D_{2} \quad$ average channel depth of channel 2

$g \quad$ acceleration caused by gravity

$h_{f} \quad$ frictional head loss

$h_{j} \quad$ local frictional loss

$l \quad$ island length

$L_{P} \quad$ length of flow path

$L_{P 1} \quad$ length of channel 1

$L_{P 2} \quad$ length of channel 2

$P_{S 1} \quad$ proportion of sediment discharge in channel 1

$P_{s 2} \quad$ proportion of sediment discharge in channel 2

$P_{w 1} \quad$ proportion of water discharge in channel 1

$P_{w 2} \quad$ proportion of water discharge in channel 2

$q_{b} \quad$ bedload transport rate per unit channel width

$q_{b}{ }^{*} \quad$ dimensionless bedload transport rate per unit channel width

$Q \quad$ flow discharge

$Q_{1} \quad$ water discharges in channel 1

$\mathrm{Q}_{2} \quad$ water discharges in channel 2

$Q_{s} \quad$ total sediment discharge

$Q_{s 1} \quad$ sediment discharges in channel 1

$Q_{\text {s2 }} \quad$ sediment discharges in channel 2

$Q_{\text {max }} \quad$ maximum sediment discharge carrying capacity

$R \quad$ hydraulic radius

$S \quad$ channel slope

$S_{\min } \quad$ minimum energy slope

$S_{1 \text { min }} \quad$ minimum energy slope in channel 1

$S_{2 \min } \quad$ minimum energy slope in channel 2

$V \quad$ average flow velocity

W channel width

$W_{1} \quad$ channel width of channel 1

$W_{2} \quad$ channel width of channel 2

$\tau_{0}^{*} \quad$ dimensionless shear stress

$\tau_{c}^{*} \quad$ dimensionless critical shear stress

$\rho \quad$ specific density of water

$\rho_{s} \quad$ specific density of sediment grains

$\zeta \quad$ width/depth ratio $(W / D)$

$\zeta_{m} \quad$ value of $\zeta$ at which $S_{\min }$ is achieved

$\zeta_{1 m} \quad$ value of $\zeta_{1}$ at which $S_{1 \text { min }}$ is achieved

$\zeta_{2 m} \quad$ value of $\zeta_{2}$ at which $S_{2 m i n}$ is achieved

\section{References}

Ashworth, P.J., Lewin, J., 2012. How do big rivers come to be different? Earth-Sci. Rev. 114 (s1-2), 84-107.

Baker, V.R., Kochel, R.C., 1979. Martian channel morphology - Maja and Kasei Valles. J. Geophys. Res. 84 (B14), 7961-7983.

Cai, D., Li, Q., 2011. River channel evolution and characteristics of navigation-obstruction in Daijiazhou section in the middle Yangtze River. J. Sediment. Res. 2, 47-54 (In Chinese).

Cao, G., 2012. Channel Evolution of the Yangtze River on Jiangsu Reach since the LGM and the Temporal-Spatial Variation of the Channel during the last 44 Years, Nanjing, China Thesis for Doctor of Engineering Nanjing Normal University (In Chinese)

Carling, P., Jansen, J., Meshkova, L., 2014. Multichannel rivers: their definition and classification. Earth Surf. Process. Landf. 39, 26-37.

Dai, Z., Liu, J.T., 2013. Impacts of large dams on downstream fluvial sedimentation: An example of the Three Gorges Dam on the Changjiang (Yangtze River). J. Hydrol. 480, 10-18.

du Boys, M.P., 1879. Le Rhone et le rivieres a lit affoillable. Mem. Doc. Ann. Pont et Chaussees Ser. 5 18, 141-195.

Eaton, B.C., Giles, T.R., 2009. Assessing the effect of vegetation-related bank strength on channel morphology and stability in gravel-bed streams using numerical models Earth Surf. Process. Landf. 34 (5), 712-724.

Eaton, B.C., Millar, R.G., Davidson, S., 2010. Channel patterns: braided, anabranching, and single-thread. Geomorphology 120 (3), 353-364.

Frias, C.E., Abad, J.D., Mendoza, A., Paredes, J., Ortals, C., Montoro, H., 2015. Planform evolution of two anabranching structures in the Upper Peruvian Amazon River. Water Resour. Res. 51, 2742-2759.

Guan, L., 2010. The fluvial processes of Jiangxinzhou island and branches of Maanshan reach. Jianghuai Water Resources Science and Technology 4, 22-24 (In Chinese). 
Gurnell, A.M., Petts, G.E., 2002. Island-dominated landscapes of large floodplain rivers, a European perspective. Freshw. Biol. 47, 581-600.

Hong, J., Liao, X., 2012. River regulation project in Maanshan reach of the lower Yangtze River. Journal of Yangtze River Scientific Research Institute 29 (2), 1-5 (In Chinese)

Huang, L., 2008. Variation of Water and Sediment Load and Impacts on the Transversal Profile in Jianli Reach of the Changjiang (Yangtze) River, Wuhan, China Thesis for Master of Engineering Changjiang River Scientific Research Institute (In Chinese).

Huang. H.Q., 2010. Reformulation of the bed load equation of Meyer-Peter and Müller in light of the linearity theory for alluvial channel flow. Water Resour. Res. 46 (W09533), 1-11.

Huang, H.Q., Chang, H.H., 2006. Scale independent linear behavior of alluvial channel flow. J. Hydraul. Eng. 132 (7), 722-730.

Huang, H.Q., Nanson, G.C., 2000. Hydraulic geometry and maximum flow efficiency as products of the principle of least action. Earth Surf. Process. Landf. 25, 1-16.

Huang, H.Q., Nanson, G.C., 2001. Alluvial channel-form adjustment and the variationa principle of least action. Proceedings of the XXIX IAHR Congress, Beijing, Theme D 410-415.

Huang, H.Q., Nanson, G.C., 2002. A stability criterion inherent in laws governing alluvial channel flow. Earth Surf. Process. Landf. 27, 929-944.

Huang, H.Q., Nanson, G.C., 2007. Why some alluvial rivers develop an anabranching pattern. Water Resour. Res. 43 (W07441), 1-14.

Huang, H.Q., Nanson, G.C., Fagan, S.D., 2002. Hydraulic geometry of straight alluvial channels and the principle of least action. J. Hydraul. Res. 40, 153-160.

Huang, H.Q., Chang, H.H., Nanson, G.C., 2004. Minimum energy as the general form of critical flow and maximum flow efficiency and for explaining variations in river channel pattern. Water Resour. Res. 40 (4), 285-285.

Huang, H.Q., Deng, C.Y., Nanson, G.C., Fan, B.L., Liu, X.F., Liu, T.H., Ma, Y.X., 2014. A test of equilibrium theory and a demonstration of its practical application for predicting the morphodynamics of the Yangtze River. Earth Surf. Process. Landf. 39, 669-675.

Institute of Geography of CAS, Yangtze River Scientific Research Institute, Changjiang Waterway Planning Design and Research Institute, 1985. The Channel Characteristics and Evolution in the Middle and Lower Yangtze River. Science Press, Beijing (In Chinese).

Jansen, J.D., Nanson, G.C., 2004. Anabranching and maximum flow efficiency in Magela Creek, northern Australia. Water Resour. Res. 40, W04503.

Jansen, J.D., Nanson, G.C., 2010. Functional relationships between vegetation, channe morphology, and flow efficiency in an alluvial (anabranching) river. J. Geophys. Res. - Atmos. 115 (F4), 817-824.

Knighton, A.D., Nanson, G.C., 1993. Anastomosis and the continuum of channel pattern. Earth Surf. Process. Landf. 18, 613-625.

Komar, P.D., 1983. Shapes of streamlined islands on Earth and Mars: experiments and analyses of the minimum-drag form. Geology 11, 651-654.

Latrubesse, E.M., 2008. Patterns of anabranching channels: the ultimate end-member adjustment of mega rivers. Geomorphology 101, 130-145.

Latrubesse, E.M., 2015. Large rivers, megafans and other Quaternary avulsive fluvial systems: a potential "who's who" in the geological record. Earth-Sci. Rev. 425, 1-30.

Latrubesse, E.M., Franzinelli, E., 2005. The late Quaternary evolution of the Negro River, Amazon, Brazil: implications for island and floodplain formation in large anabranching tropical systems. Geomorphology 70, 372-397.

Leopold, L.B., Wolman, M.G., 1957. River Channel Patterns: Braided, Meandering and Straight. United States Geological Survey Professional Paper.

Lu, Y., Ping, K., Liu, W., 2012. Macro analysis of alluvial process from Jiangxinzhou to Wujiang reach in the Yangtze River. Journal of Waterway and Harbor 33 (4), 315-320 (In Chinese).

Luo, H.C., 1989. Characteristics of fluvial processes and stability of the braided channel in the middle and lower reaches of the Yangtze River. J. Hydraul. Eng. 6, 10-18 (In Chinese).
Lv, X., 2011. River channel evolution analysis in Huangshi reach of the Yangtze River. Yangtze River 42 (4), 12-15 (In Chinese).

Marchetti, Z.Y., Latrubesse, E.M., Pereira, M.S., Ramonell, C.G., 2013. Vegetation and its relationship with geomorphologic units in the Parana River floodplain, Argentina. J. S. Am. Earth Sci. 46 (9), 122-136.

Meshkova, L.V., Carling, P.A., 2012. The geomorphological characteristics of the Mekong River in northern Cambodia: a mixed bedrock-alluvial multi-channel network. Geomorphology 147 (8), 2-17.

Meshkova, L.V., Carling, P.A., 2013. Discrimination of alluvial and mixed bedrock-alluvial multichannel river networks. Earth Surf. Process. Landf. 38 (11), 1299-1316.

Meyer-Peter, E., Müller, R., 1948. Formulas for bed-load transport. Proceedings of the 2nd Meeting of IAHR, Stockholm, pp. 39-64.

Millar, R.G., 2000. Influence of bank vegetation on alluvial channel patterns. Water Resour. Res. 36 (4), 1109-1118.

Nanson, G.C., Huang, H.Q., 1999. Anabranching rivers: divided efficiency leading to fluvial diversity. In: Miller, A.J., Gupta, A. (Eds.), Varieties of Fluvial Form. John Wiley, Hoboken, N. J., pp. 477-494.

Nanson, G.C., Huang, H.Q., 2008. Least action principle, equilibrium states, iterative adjustment and the stability of alluvial channels. Earth Surf. Process. Landf. 33, 923-942.

Nanson, G.C., Knighton, A.D., 1996. Anabranching rivers: their cause, character and classification. Earth Surf. Process. Landf. 21, 217-239.

Ni, J.R., 1994. Anabranched rivers. J. Chin. Geogr. 4, 91-101.

Parker, G., 1976. On the cause and characteristic scales of meandering and braiding in rivers. J. Fluid Mech. 76, 457-480.

Parker, G., Wilcock, P.R., Paola, C., Dietrich, W.E., Pitlick, J., 2007. Physical basis for quasiuniversal relations describing bankfull hydraulic geometry of single-thread gravel bed rivers. J. Geophys. Res. Earth Surf. 112 (F4), 215-226 (2003-2012).

Tooth, S., McCarthy, T.S., 2004. Anabranching in mixed bedrock-alluvial rivers: the example of the Orange River above Augrabies Falls, Northern Cape Province, South Africa. Geomorphology 57, 235-262.

Tooth, S., Nanson, G.C., 1999. Anabranching rivers on the northern plains of arid central Australia. Geomorphology 29, 211-233.

Tooth, S., Nanson, G.C., 2000. The role of vegetation in the formation of anabranching channels in an ephemeral river, Northern plains, arid central Australia. Hydrol. Process. 14, 3099-3117.

Tooth, S., Jansen, J.D., Nanson, G.C., Coulthard, T.J., Pietsch, T., 2008. Riparian vegetation and the late Holocene development of an anabranching river: Magela Creek, northern Australia. Geol. Soc. Am. Bull. 120, 1021-1035.

Wende, R., Nanson, G.C., 1998. Anabranching rivers: ridge-form alluvial channels in tropical northern australia. Geomorphology 22 (3), 205-224.

Wong, M., Parker, G., 2006. Reanalysis and correction of bed-load relation of Meyer-Peter and Müller using their own database. J. Hydraul. Eng. ASCE 132, 1159-1168.

Xu, F., Yue, H., 2008. Analysis on river evolution near the training works at the head of Tianxing bar. Port Eng. Technol. 1, 13-16 (In Chinese).

You, L.Y., 1984. A study on the formation and evolution of an anabranching river with stable islands - taking the middle and lower reaches of the Yangtze River as an example. Geogr. Res. 3 (4), 12-24 (In Chinese).

Yu, W.C., Lu, J.Y., 2005. Fluvial Process and River Engineering of the Yangtze River. Water Resources and Hydropower Press, Beijing (In Chinese).

Yu, J., Liao, Y., Zhang, P., Gao, C., 2012. Characteristics of soil particle size distribution and fractal dimension in a channel island in the lower reach of the Yangtze River. Chin. J. Ecol. 31 (3), 626-631 (In Chinese).

Zanoni, L., Gurnell, A., Drake, N., Surian, N., 2008. Island dynamics in a braided river from analysis of historical maps and air photographs. River Res. Appl. 24 (8), 1141-1159. 